\title{
Representaciones de la ciudad ayacuchana en dos películas peruanas, durante el conflicto armado interno
}

\author{
James A. Dettleff \\ Pontificia Universidad Católica del Perú \\ jdettleff@pucp.edu.pe
}

Recibido: 18/7/2018 / Aceptado: 26/9/2018

doi: 10.26439/contratexto2018.n030.3155

\begin{abstract}
Resumen. En los últimos veinte años del siglo pasado, el Perú vivió la etapa de violencia más grande de su historia, la cual dejó más de 69000 víctimas. Finalizado el conflicto, la ficción cinematográfica - entre otros- empezó a abordarlo, tanto desde la capital como desde Ayacucho, ciudad con la mayor cantidad de víctimas. La ciudad andina ha estado casi ausente de la cinematografía limeña, mientras que ha sido el espacio común donde se desarrollan las acciones en la cinematografía ayacuchana. Esta visión reproduce una mirada de cómo se vivió el conflicto armado interno (CAI) peruano en la costa y en el ande. En este artículo analizamos la representación cinematográfica de Ayacucho en dos películas: Sangre inocente, de Palito Ortega, y La última noticia, de Alejandro Legaspi. La ciudad es el espacio por donde discurren los personajes y donde se dan las acciones que los enfrentan al conflicto armado. Este trabajo es abordado a partir de un acercamiento cualitativo: se examinan las películas a través de matrices que identifican los elementos configuradores de las ciudades como espacio de vida de la población durante el CAI, y se analiza cómo las películas pueden configurarse como un artefacto cultural que permite construir memoria sobre lo que fue el pasado y sobre cómo fue la vida de los habitantes urbanos andinos durante esa época.
\end{abstract}

Palabras clave: representación / cine / conflicto armado interno / terrorismo / ciudad / Perú 


\title{
Representations of Ayacucho during the internal armed conflict in two Peruvian films
}

\begin{abstract}
Авstract. In the last twenty years of the last century, Peru lived its biggest era of violence, which ended up with over 69,000 victims. Once the conflict was finished, filmmakers -among other cultural producers- from both the Peruvian capital and from Ayacucho -which holds the most victims- started to tell what happened during those years. The Andean city has been absent in almost all films produced in Lima, while it has been the recurrent space of films produced in Ayacucho. This approach reproduces how people lived the internal armed conflict (ICA) in the Peruvian coastal and Andean regions. In this paper, we analyze the film representation of Ayacucho in two films: Sangre inocente, directed by Palito Ortega and La última noticia, directed by Alejandro Legaspi. The city is the place where characters are and where actions that make them face the ICA take place. This work uses a qualitative method, examines the films with matrixes which enable us to identify the key elements that configure the cities as living places of the civil population during the ICA, and analyzes how films can become a cultural artifact that allows us to build memory about the past and the urban Andean inhabitants' life during that era.
\end{abstract}

Keywords: representation / film / internal armed conflict / terrorism / city / Peru 
Un país que olvida su historia está condenado a repetirla.

Comisión de la Verdad y Reconciliación, s. f.

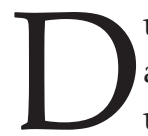
urante los últimos veinte años del siglo xx, el Perú vivió una de las guerras internas más sangrientas de su historia. En el presente siglo, el país ha desarrollado un discurso oficial que aboga por la reconciliación nacional con el nombramiento de la Comisión de la Verdad y la Reconciliación (en adelante, CVR), un informe final de ella, leyes sobre reparaciones civiles, muestras fotográficas, espacios de memoria, entre otros. La labor del Lugar de la Memoria, la Tolerancia y la Inclusión Social (LUM) es ser un espacio de encuentro para los peruanos como lugar de recuerdo, pero también de reconciliación. Sus muestras y actividades relacionadas con los años del conflicto armado interno (en adelante, CAI) - nombre que se ha dado a la guerra interna- han intentado mostrar los motivos y las consecuencias de este, $\mathrm{y}$ han permitido crear una imagen de lo que significaron esos años para aquellos que no fueron testigos directos y para las nuevas generaciones de peruanos. Pero el relato de esta época está en constante disputa, como lo demuestran las presiones y posterior renuncia del director del LUM en agosto del 2017, luego de una muestra sobre hechos sucedidos en 1992, o la acusación de apología del terrorismo por la compra de tablas de Sarhua - piezas de arte popular ayacuchano- adquiridas por el Museo de Arte de Lima en enero del 2018.

Debemos entender que la configuración de la imagen del pasado de una sociedad se da por la historia estudiada en los colegios, los relatos narrados por familiares o conocidos, aquello que se aprecia en los medios, entre otros. Mirar el pasado es mirarlo desde el hoy, entender lo que sucedió para darle sentido y generar un relato que permita dar forma al pasado de la sociedad (Birulés, 1989). Por ello, es importante que desde diversos espacios se trabaje en recuperar la memoria de la época del CAI, que nos permita comprender - a los peruanos y a los extranjeros- aquello que sucedió en esos años para intentar evitar que se repita y no permitir que los culpables evadan responsabilidades. Varios políticos, exmilitares y civiles peruanos que cumplieron acciones determinantes en los años del CAI pretenden olvidar esa época y minimizar sus responsabilidades.

\section{Contexto: el conflicto armado interno peruano}

El CAI se inició en el departamento andino de Ayacucho en mayo de 1980, cuando miembros de Sendero Luminoso robaron y quemaron las ánforas de votación en el pequeño poblado de Chuschi, acto simbólico que Sendero Luminoso denominó el Inicio de la Lucha Armada (Degregori, 2011). El CAI enfrentó a las Fuerzas Armadas del Estado principalmente contra dos grupos terroristas: Sendero Luminoso, grupo organizado por 
intelectuales y académicos de izquierda relacionados a sindicatos de docentes en Ayacucho, cuya idea era llevar la lucha "del campo a la ciudad"; y el Movimiento Revolucionario Túpac Amaru (MRTA), que inició sus acciones subversivas en 1984. Mientras a Sendero Luminoso lo caracterizó el secretismo, el hermetismo y lo absolutamente clandestino, al MRTA lo caracterizó la búsqueda de publicitar sus acciones y reivindicar sus atentados ${ }^{1}$.

Al finalizar el conflicto, la CVR calculó el número de víctimas fatales en 69 280, el $75 \%$ de ellas eran quechuahablantes. La mayoría de las víctimas fueron pobladores de los Andes y de la selva peruana, pertenecientes a las clases menos empoderadas del país (Comisión de la Verdad y Reconciliación [CVR], 2004). El CAI se desarrolló en veintitrés de los veinticinco territorios en que está dividido el Perú (veinticuatro departamentos y una provincia constitucional), y en solo dos de ellos el número de víctimas fue de un dígito (Degregori, 2011). El $40 \%$ de las víctimas del CAI se dieron en el departamento de Ayacucho, que tuvo el mayor porcentaje de muertos y desaparecidos de todos los departamentos.

La manera en que el conflicto se ha representado condiciona la forma en que se recuerda esa época, y las posibilidades de reconciliación van a depender de cómo nos hemos visto los peruanos, cómo recordamos o construimos nuestra memoria sobre lo que hicimos durante esa época y qué responsabilidades tenemos.

Desde el año 1988 hasta la actualidad se han realizado en el Perú casi treinta películas y series televisivas que abordan el accionar de las Fuerzas Armadas, la población o las acciones de los grupos terroristas. La dimensión simbólica de estos relatos aporta en la constitución de la memoria del país sobre esa época, pues han representado situaciones difíciles de imaginar y permitido que se conozcan hechos poco recordados. La información que actualmente se posee de los sucesos es diferente a la de los años del propio conflicto, gracias al trabajo de la CVR, a los juicios a algunos responsables y al trabajo que realizan diferentes colectivos sociales, cívicos y de derechos humanos. Además, las condiciones de producción audiovisual son distintas y las mayores facilidades tecnológicas permiten miradas desde diferentes partes del país - y no solo desde Lima-, lo cual permite afirmar que la representación de lo sucedido en esa etapa ha variado. Estas producciones de ficción reconstruyen la realidad de esa época pasada y la manera en que esto se hace, los elementos que se priorizan y los que se excluyen, postulan relatos y memorias diferentes (Jelin, 2002).

1 En 1984, el MRTA secuestró a dos periodistas de Frecuencia Latina y exigió al canal que emitieran una proclama suya y una entrevista hecha por los periodistas. En años posteriores, varias veces tomaron locales radiales para emitir proclamas y declaraciones políticas. 


\section{El concepto de representación}

El término representación puede acercarse al concepto aristotélico de mímesis, que alude a que la imitación es algo connatural al hombre (Aristóteles, s. f./trad. 1999), así como al concepto de emulación. Para Foucault, la representación tiene de reflejo y de espejo, es una visión dispersa de las cosas del mundo más que una imitación natural y transparente (Foucault, 1968). Sin embargo, estas ideas suponen que el significado de aquello representado es un reflejo del significado inherente a los objetos o sujetos (Foucault, 1968; Hall, 2003; Marin, 2001) y no permite observar con claridad el proceso de construcción que existe en la representación.

Toda representación lo es de un sujeto u objeto (Jodelet, 2008; Moscovici, 1979), y tiene una función expresiva. En el acto de la representación, al objeto o sujeto representado "se le confiere categoría de signo, haciéndolo significante" (Moscovici, 1979, p. 40). Esta visión es denominada construccionista y sostiene que el lenguaje y los signos operan como un sistema de representación, pues se refieren a algo que no está presente, a conceptos abstractos o a elementos con los que uno no ha tenido experiencia directa, y les otorgan sentido o significado que podrá ser interpretado por quienes compartan el código (Hall, 2003; Klinkenberg, 2006). Esta visión difiere de aquella que simplemente ve un reflejo del significado inherente de las cosas, que suponía que los signos están en la realidad y que el hombre debía descifrarlos (Foucault, 1968; Potter, 1998), o de la llamada visión intencional, que supone que el significado está dado por quien enuncia el lenguaje (Potter, 1998), el cual es considerado como el principal sistema de representación (Hall, 2003; Zecchetto, 2002).

Lo construccionista (o constructivista) supone la interacción de quien enuncia y de quien recibe el mensaje; plantea que se representa al mundo y se le carga de significado no imitándolo, sino construyéndolo a partir de un intercambio de sentido de los miembros de una cultura (Hall, 2003), y, por ello, esta construcción se realiza desde una visión determinada o enmarcada dentro de los parámetros de esa cultura. Una vez que el significado se fija, que lo abstracto se materializa, aparece como algo natural o real, haciendo que olvidemos el proceso de creación en esa representación (Moscovici, 1979), eliminando el concepto de motivación y reconstrucción (Klinkenberg, 2006), lo que hace que se asuma de modo práctico sin atribución de referencias sociales (Rodríguez, 2002).

El significado que se le otorga al mundo se genera a partir de las convenciones sociales que lo nominan y son parte de la forma en que aquellos que lo nominan entienden y observan al mundo (Marin, 2001, p. 314). De esta manera, una representación puede tener un significado para un grupo cultural, pero uno diferente para otro, según lo que Jodelet llama "horizontes" en los sistemas de representación transubjetivos (Jodelet, 2008, p. 57), o a través de lo que la semiótica denomina paradigmas 
culturales y contextos (Zecchetto, 2002), ya que a partir de ellos se afirman conceptos, categorías o nociones que permiten a los sujetos explicar su entorno (Rodríguez, 2002, p. 36) con formas de referencia compartidas, las cuales serán dinámicas $\mathrm{y}$ tendrán mayor $\mathrm{o}$ menor presencia en momentos determinados (Moscovici, 1988). Existen diferentes formas de referencia que buscan lograr hegemonía ${ }^{2}$ en la construcción de las representaciones mentales que permiten a una sociedad darle sentido al mundo (Hall, 2003, p. 17).

Una imagen, una obra teatral o cinematográfica son formas de representación, reconstrucciones de la realidad generadas a partir de marcos culturales que dan sentido para los grupos desde donde se procesa la representación. Gledhill indica que, como cualquier otra práctica social, las representaciones están saturadas de significados y valores (Gledhill, 2003), y nos ofrecen un punto de vista sobre lo representado, afectando la manera en que será leído por los demás miembros de la sociedad. Las representaciones son el resultado de una producción social, discursos sociales creados con fines específicos (Zecchetto, 2002), y los miembros de esa sociedad harán la lectura de esos discursos de acuerdo a las formas de interpretación o decodificación que se comparten socialmente (Hall, 2003).

\section{La memoria como reconstrucción del pasado}

Mirar el pasado es hacerlo desde el hoy, entender aquello que sucedió para darle sentido y generar un relato que, desde el presente, permita dar forma a aquellos momentos que se han convertido en parte de la sociedad.

Los individuos damos nueva presencia a los eventos del pasado a través de la memoria, generando relatos que nos permiten darles sentido, tanto personal como público (White, 2003, p. 115). Hoskins indica que para generar una memoria se requiere una reconstrucción del evento, persona o lugar (Hoskins, 2001, p. 335); la memoria se constituye no en un "algo" específico ni fijo, no es algo que se recupera de algún sitio ni está almacenado en ningún lado (como la mente), sino que es un proceso de creación, es algo que los individuos hacemos o creamos, no algo que tenemos (Halbwachs, 1995; Olick, 2008).

El pasado no es un elemento autónomo y discreto, sino que está mezclado con el presente y se actualiza en él (Cárdenas, 2012; Rezende, 2013; Sturken,

2 El término hegemonía se utiliza aquí en el sentido trabajado por Gramsci, quien considera que, frente a distintas ideologías o posiciones, una no anulará a las demás, sino que tomará un lugar hegemónico dependiendo del momento y espacio histórico; de esta forma, todas coexisten, aunque una con mayor presencia que las demás. 
1997b). Esta actualización permite a los individuos crear lo que Edgerton llama un "pasado útil", una actualización de hechos pasados que permitan generar sentido, lo cual faculta que se aclare el presente y se piense el futuro (Edgerton, 2005). De esta forma, se otorga un sentido al pasado, aunque de manera retrospectiva, desde el hoy (Birulés, 1989), ya que lo que se tiene son fragmentos del pasado que solamente pueden constituirse como memoria gracias a los esquemas que nos otorgan de manera colectiva en el presente los individuos con los que interactuamos y los medios que utilizamos (Erll, 2008; Marcel y Mucchielli, 2008).

La (re)construcción de la memoria, en términos de Hoskins (2001), significa generar una representación, la cual creará sentido a partir de aquello que se recuerde a la luz de la interpretación que se haga desde el presente (Ankersmit, 1988; Birulés, 1989). Pero esa reconstrucción no será de modo alguno transparente, pues, así como pasado y presente están ligados, también lo están la memoria y el olvido (Sturken, 1997b). El proceso de reconstrucción supone, por tanto, que este cuente con elementos recordados, pero habrá ausencia de aquello que ha sido olvidado o silenciado (Jelin, 2001). De esta manera, en la reconstrucción del pasado habrá selección, sesgo, posiciones desde las cuales se reconstruye, lo que marcará su interpretación y lectura en el presente.
Erll (2008) indica que sin sujetos orgánicos que relaten el pasado, la memoria depende de los diferentes medios físicos para transmitir la experiencia: se articula a través de procesos de representación en objetos o imágenes, los cuales se convierten en tecnologías de la memoria ${ }^{3}$ que permiten producir y dar sentido (Sturken, 1997b, p. 9). Sin embargo, debe entenderse que esos objetos son productores de memoria y no receptáculos donde esta reside, pues el significado irá construyéndose dependiendo del tiempo, las prácticas sociales y el contexto en que se realice esa construcción, por lo cual se afirma que la memoria no se mantiene estática ni es monolítica (Olick, 2008).

Vista de esta manera, la memoria puede reconstituirse a partir de imágenes - como las del cine- que refieren a sucesos anteriores y hacer que el acontecimiento vivido se convierta en un acontecimiento sin barreras en la memoria (Benjamin, 1929, p. 1). En palabras de Benjamin, en la memoria como hecho personal se genera una "presentización" del acontecimiento a partir de la aparición de elementos aislados generados por la "memoria involuntaria" - gatillada por una imagen, un suceso, un sabor - que configuran sentido al convertirse en parte de nuestra memoria (Benjamin, 1929, pp. 6-7).

Los medios visuales pueden ser utilizados como formas que permitan

3 Aquí Sturken hace uso del término tecnología en el sentido foucaultiano de prácticas sociales que implican dinámicas de poder. 
relacionarse con el pasado, y en la actualidad mucho del conocimiento que se genera sobre eventos anteriores se da gracias a productos audiovisuales antes que a partir de textos escritos (Rosenstone, 1995, p. 23). La narración es una característica de la memoria que comparte con los relatos audiovisuales. Así, recordar no es repetir una experiencia, sino narrarla, reconstruirla a través de un relato (Sturken, 1997a) que se enuncia a partir de la conclusión del hecho y desde la perspectiva del momento desde el cual se está narrando (Birulés, 1989).

\section{La memoria cultural}

La utilización del término memoria cultural subraya que esta es compartida fuera del discurso histórico formal a través de productos culturales que contienen un orden simbólico. El término supone un espacio de negociación cultural a través de diferentes relatos que buscan su lugar en la historia (Sturken, 1997b, p. 1). El relato de la memoria cumple una función social, la cual se construye en contextos culturales que permiten dar sentido al pasado desde el presente, para ser interpretado por otros, en una ratificación de la memoria. Por ello, algunos autores (Erll, 2008; Erll y Rigney, 2010; Hoskins, 2001; Neiger, Meyers y Zandberg, 2011; Nora, 2008; Sturken, 1997b, 2007) estudian los productos y espacios culturales desde donde la memoria se produce. Los medios audiovisuales, y el cine en particular, son productos que pueden permitir la producción de memoria cultural.
Arjun Appadurai afirma que los medios de comunicación "transforman el campo de la mediación masiva porque ofrecen nuevos recursos y nuevas disciplinas para la construcción de la imagen de uno mismo y de una imagen del mundo" (Appadurai, 2001, p. 19), una que reedifica la realidad más allá de los espacios geográficos. Es una reconstrucción de sucesos, hechos, personajes, que puede darse también sobre entornos cercanos tanto física como temporalmente. La versión emitida - reconstrucción- se convierte en un documento que finalmente se aprehende como un hecho factual, verosímil, aunque el producto sea una ficción audiovisual.

El CAI ha sido representado de diferentes maneras en productos culturales: artículos de prensa escrita, radial y televisiva; piezas de arte popular, como los retablos, los mates burilados, las tablas de Sarhua, y en documentales y ficciones televisivas y cinematográficas. En el caso de las producciones audiovisuales, la representación de hechos reales puede configurar una memoria que se produce gracias a estos productos culturales, pero con los sesgos de la selección y el punto de vista. Cuando esta reconstrucción del pasado se realiza con afanes realistas, habrá que considerar los referentes a sucesos y personajes reales, la agencia de los diferentes sujetos en las situaciones que enfrenten y prestar especial atención a similitudes y diferencias, a aquello que se incluye o excluye (Fairclough, 2003, p. 136), lo que no es dicho o mostrado, aquellas ausencias e invisibilizaciones que pueden resultar significantes en la 
construcción de la realidad representada (Rose, 2002, p. 219).

Las películas, como artefactos culturales, aportan a la construcción de la memoria de un grupo social, y se genera un efecto de realidad a partir de la verosimilitud del relato. Los motivos libres o indicios, los modelos y los elementos de ilustración son algunos de los componentes que utiliza la narración para la construcción de la verosimilitud y para hacer referencia a hechos de la realidad. Cuando tenemos relatos con base en hechos reales - como es el caso del CAI-, esta construcción puede presentar patrones más demarcados, pues se trata de establecer una lógica y un mundo no solo al interior del universo de la narración, sino también del mundo "real".

En la construcción lógica de un relato cinematográfico se observan elementos que resultan importantes para la verosimilitud y la narración interna, como son las construcciones causales de las acciones de los personajes en diferentes escenas, los hechos que se suceden y tienen consecuencias en las escenas siguientes. Su lógica y valor se construyen en la diégesis del relato. Tomashevski (1978) llama a estos elementos motivos asociados, y Barthes (1987), funciones distribucionales o distributivas. Existen para que al ver (o leer) ${ }^{4}$ una narración exista una lógica de los hechos que suceden y del comportamiento de los personajes, más allá de si es un relato histórico o de ciencia ficción.

Pero también existe lo que Ginzburg (2013) denomina indicios, y Tomashevksi, motivos libres: aquellos que no participan en el encadenamiento causal inmediato $y$ que son detalles que aparecen en determinados momentos (Tomashevski, 1978, p. 204). Barthes resalta cómo su sola existencia genera un significado en sí misma al estar presente, al comprobar la existencia de la realidad:

La misma carencia de significado en provecho del simple referente se convierte en el significante mismo del realismo: se produce un efecto de realidad, base de esa verosimilitud inconfesada que forma la estética de todas las obras más comunes de la modernidad. (Barthes, 1987, p. 218)

El efecto de realidad al que se refiere Barthes se relaciona con lo que se conoce como el pacto o promesa de realidad. En la representación de los hechos del CAI, deberemos observar cómo se presentan los productos cinematográficos, cuál es su promesa de realidad y qué indicios utilizan para hacer referencia a los hechos del conflicto como parte de un relato que se supone real. Como indica Ankersmit (1988, 2010), no se trata de buscar una descripción de la realidad, pues no es esto lo que hacen las películas con base en sucesos reales; ellas

4 Los autores se refieren más a relatos escritos, pero sus postulados se pueden utilizar en productos audiovisuales narrativos. 
representan y construyen, y va dándose lo que Heyne (1987) denomina adecuación factual, la cual se debe observar para establecer qué tan adecuada resulta respecto del relato oficial de los hechos recopilados por la CVR.

Varias películas que tienen al CAI como tema central, más que referirse a un hecho concreto, componen un modelo determinado a partir de diferentes hechos o personajes que permiten presentar una narración que ilustre lo ocurrido en varias situaciones, pero asimiladas en una sola. Weingarten utiliza el ejemplo de John Hersey, quien creó un soldado-modelo a partir del testimonio de varios soldados; es decir, las experiencias fueron relatadas como si hubieran sido vividas por el soldadomodelo de Hersey. A pesar de lo artificial del recurso, Weingarten reconoce que esta manera de relatar otorgó a Hersey una herramienta más poderosa para narrar los acontecimientos (Weingarten, 2006, p. 187).

Identificar y analizar la utilización de indicios, referentes, modelos o ilustraciones sobre el CAI en las películas permitirá revelar la construcción que se hace, desde la realización, de los sucesos o personajes, y una posible intención de lo que se pretende narrar.

\section{El cine en el Perú}

El Perú no ha contado con una verdadera industria cinematográfica a lo largo de su historia. Su producción ha respondido más bien a un esfuerzo casi artesanal e individual de interesados en el cine que deseaban producir una película y luego buscaban formas de exhibirla. En el Perú, hablar de cine, durante muchos años, ha sido hablar de películas realizadas en Lima. Con contadas excepciones, como la escuela del Cusco de los años cincuenta y sesenta, o el cine indigenista de los setenta, la cinematografía peruana ha sido una cinematografía limeña, en el sentido de que la casa productora se encontraba en Lima, aunque los directores no fueran limeños, o la película no se filmara en la capital peruana.

El gran cambio para la producción cinematográfica en el Perú fue el tecnológico. La aparición del video digital, la posibilidad de grabar y editar en video, y la de exhibir sin depender de laboratorios extranjeros, permitieron el ingreso de nuevos realizadores, no solo limeños, sino también de las demás regiones del país. Mientras en las últimas dos décadas del siglo xx (1980-1999) se exhibieron 56 películas peruanas de ficción, en los primeros diecisiete años de este siglo (2000-2016) se exhibieron 276 películas peruanas de ficción. En el primer periodo, solo ocho películas fueron producidas fuera de Lima, mientras que en este siglo lo fueron 152. Estas últimas conforman lo que se ha llamado cine regional peruano (Bedoya, 1995, 2009; Bustamante y Luna Victoria, 2017; https://www.cinencuentro.com).

Es importante señalar que las cifras sobre el cine producido fuera de Lima son las más difíciles de establecer, pues muchas de estas películas son realizadas en formatos digitales no 
profesionales y son distribuidas por los propios directores, que van llevando su película en formato digital a diferentes ciudades y alquilan teatros donde las exhiben (Bustamante y Luna Victoria, 2014), pero en algunos casos no se puede comprobar que las películas hayan sido realmente exhibidas.

Ayacucho y Puno han sido de las ciudades donde se ha dado con mayor fuerza la producción fuera de Lima. En un primer momento, a estas producciones se le denominó cine provinciano, pero al tener este término una connotación negativa, se le ha denominado cine regional. Bustamante y Luna Victoria (2014) indican que los realizadores también encuentran este nombre despectivo y que prefieren que se hable simplemente de cine peruano. Los autores indican que, a pesar de que los realizadores tienen razón, hacerlo significaría invisibilizarlos y no darles una identidad propia (Bustamante y Luna Victoria, 2014).

\section{El conflicto armado interno en dos películas peruanas}

El CAI se desarrolló en prácticamente todo el territorio peruano, en las zonas rurales y en las zonas urbanas. La ciudad de Ayacucho -también conocida como Huamanga - fue una de las más afectadas, y sus pobladores debieron convivir con la creciente presencia de elementos de las Fuerzas Armadas y miembros de Sendero Luminoso. Ayacucho, como espacio donde se desarrolló el conflicto armado, ha sido para muchos un nombre más que un verdadero lugar, un espacio abstracto que era cuna del terrorismo y lugar de conflicto, pero no un lugar de vida, desarrollo, posibilidades o carencias. Ciudad colonial con tradición religiosa, Ayacucho no contaba, hasta la década de los ochenta del siglo pasado, con una representación tan amplia como la de otras ciudades andinas importantes en el Perú; por ejemplo, Cusco o Arequipa. El CAI hace que esa representación menos frecuente de Ayacucho aumente y se agudice, ya que se centra en ella como un espacio de conflicto más que como una ciudad donde habitan sus ciudadanos.

La cinematografía peruana ha abordado poco la ciudad de Ayacucho como espacio de sus representaciones para el CAI. De veintidós películas con alguna temática o referencia directa al CAI estrenadas entre el 2000 y el 2016, la mitad desarrolla su historia en los Andes peruanos y solo cinco lo hacen en la ciudad de Ayacucho. Ya que lo que nos interesa son las representaciones del conflicto armado, no podemos dejar de pensar en la manera en que se han representado los espacios donde este tuvo lugar. Si bien el conflicto se da entre las personas y sus acciones, estas se desenvuelven en espacios específicos que condicionarán a aquellos que lo habitan, y creará marcas para su reconstrucción posterior, indicios que permitirán una mirada de aquello que quedó después de finalizado el conflicto.

De esta forma, nos guían las siguientes preguntas: ¿dónde se desarrolló el CAI según las representaciones cinematográficas peruanas? ¿Qué características 
tienen esos lugares? ¿Cómo afectan estos espacios a las personas que los habitan? ¿Que nos dicen esas representaciones sobre lo que se recuerda del CAI?

En este trabajo presentamos el análisis de dos películas realizadas en la época posterior al CAI: Sangre inocente, realizada por Palito Ortega - director ayacuchano- y estrenada en el 2000, y La última noticia, realizada por Alejandro Legaspi -director radicado en Limay estrenada en el 2016. Debe dejarse en claro que lo expuesto en este trabajo no puede generalizarse a todas las películas que hayan tenido al conflicto armado como tema, y menos a la cinematografía peruana. Es solo un acercamiento a dos películas con orígenes distintos, realizadas en dos momentos diferentes, pero nos sirve para observar cómo, en estos dos casos analizados, se observan representaciones marcadas por el tiempo, pero también por la posición desde donde se observa y se recuerda.

Sangre inocente relata lo que sucede a Alfonso/Pochito, un humilde propietario de un puesto en el mercado de Ayacucho, quien, presionado por un viejo amigo, acepta llevar un paquete a un senderista. Las fuerzas del orden apresan a Alfonso y lo torturan buscando que delate a sus supuestos compañeros. En paralelo, sus sobrinos tratan de averiguar dónde está prisionero y buscan liberarlo. Pero en el intento, también son perseguidos como sospechosos de terrorismo. Luego de varios días de tortura, las fuerzas del orden creen que Alfonso ha muerto y lo arrojan a una quebrada, donde sus familiares lo encuentran. Finalmente, deciden que la única solución es huir de Ayacucho.

La última noticia narra la vida de Alonso, un locutor radial recién casado que impulsa la creación de un noticiero local que da cuenta de las acciones de Sendero Luminoso y de las fuerzas del orden en la ciudad y alrededores, lo que lo convierte en un elemento incómodo tanto para los terroristas como para los militares. Amenazados por ambos bandos tanto él como su familia, y asesinado su mejor amigo, decide abandonar la ciudad y su labor.

Ambas películas se presentan como relatos ficcionales, aunque Sangre inocente indica que está basada en hechos reales. Antezana y Cabalin nos indican que, aun cuando se establezcan como ficcionales, en los relatos basados en hechos reales o que refieren a sucesos y momentos de la historia de un país, sus personajes, historias y contexto son percibidos como reales y generan respuestas de esa naturaleza (Antezana y Cabalin, 2018). En las dos películas elegidas para este trabajo, la relación que construyen con el pasado permite una respuesta en el público, que las ve como relatos cercanos a sucesos verídicos, y se constituyen en huellas de un pasado que es reconstruido en el presente.

En las películas, los hechos suceden en alguna ciudad de los Andes peruanos -Ayacucho en la película de Ortega y la ficticia Yurabamba en la de Legaspi- y se ubican en momentos definidos del CAI: Sangre inocente indica explícitamente las fechas -diciembre de 1987- mientras La última noticia indica que el comienzo 
de la historia se ubica en 1982, y el relato avanza aproximadamente unos dos años.

Ambos relatos establecen acciones específicas $-\mathrm{y}$ reconocibles por una gran parte de los peruanos- con eventos que sucedieron en la época del CAI. Mientras Sangre inocente se enfoca en sucesos muy específicos de los últimos días de 1987, La última noticia alude a varios sucesos ocurridos en diferentes momentos y partes del país, en un relato que se acerca a la composición de un modelo, en los términos expuestos por Weingarten párrafos arriba. El modelo se da también en el espacio, pues, aunque La última noticia crea un lugar ficticio -Yurabamba-, una serie de indicios hacen referencia a Ayacucho y sus alrededores, por lo que hay una construcción de un espacio que podría tener características de varios lugares andinos, pero con constante anclaje en la ciudad de Huamanga/Ayacucho.

\section{La ciudad como espacio del conflicto armado interno}

En este trabajo analizamos la manera en que la ciudad está representada, observándola en cuatro espacios principales: los espacios públicos, los espacios privados, los espacios de autoridad y los lugares alrededor de la ciudad donde se lleva a cabo el relato. Seleccionando algunos lugares de estos espacios, observamos cómo están representados y la manera en que condicionan o caracterizan a los personajes que en ellos discurren, y de qué forma estos lugares reflejan el conflicto armado o permiten su representación. Observamos los indicios o motivos libres, en el sentido utilizado por Ginzburg, Tomashevski y Barthes, para generar el efecto de realidad que sustenta lo verosímil del relato sobre el pasado. Finalmente, comparamos si esas representaciones muestran características distintas entre la versión realizada desde la cinematografía costeña y aquella realizada desde la cinematografía andina.

\section{Los espacios públicos}

Por espacio público entendemos los lugares en los que cualquier persona puede circular, reunirse o entrar. Es un espacio que teóricamente no le pertenece a nadie - no cuenta con un/a "dueño/a"y que a la vez se entiende como un lugar de toda la población. La calle, las plazas y las plazuelas, el río y el mercado son algunos de los espacios públicos que pueden encontrarse en Sangre inocente. En la calle, los personajes se cruzarán con Santiago, miembro de Sendero Luminoso, quien forzará a Alfonso a entregar el paquete de dinamita. En la calle será también donde los protagonistas encontrarán en dos oportunidades los cadáveres de víctimas del conflicto, y donde Cirilo y Pepito - los jóvenes familiares de Alfonso- serán testigos del asesinato de un policía, un funeral y la marcha de un grupo senderista, así como el funeral de varios civiles.

En las plazuelas y sus calles aledañas, los protagonistas se verán en medio de un enfrentamiento entre subversivos y fuerzas del orden, deberán protegerse 
de los disparos de la batalla, se encontrarán cerca de la explosión de un auto y de una bomba que deberán manipular para evitar que mate a una joven madre.

El río es un lugar al que los personajes acudirán para reflexionar sobre lo que les está sucediendo, un espacio retirado del tránsito cotidiano de otras personas, pero que será también, en una oportunidad, el lugar donde Calamar (miembro de las fuerzas del orden) vea cómo Alfonso recoge el paquete con la dinamita.

Los mercados en Sangre inocente tendrán una doble función, pues serán espacios públicos donde la gente comercia, se congrega a escuchar misa e interactúa; pero también serán privados, como el local donde trabajan los protagonistas, en el que se refugiarán cuando se sientan vigilados. Será en el mercado, como lugar público, donde los jóvenes serán testigos del asesinato de un sacerdote.

En el caso de La última noticia, el espacio público principal $-\mathrm{y}$ prácticamente el único con utilidad narrativa - será la calle, lugar de tránsito de los personajes, que la mayoría de veces se situará como zona de tensión. Ahí encontrarán los personajes, en las primeras escenas, un perro muerto colgado en un poste y pintas en las paredes; en la calle serán detenidos Alonso y Pedro, y en otra ocasión será el lugar donde estarán expuestos a una balacera; ahí Teresa caminará decidida hacia la comandancia hasta que escuche disparos y vea a dos sujetos huir, lo que la hace volver a su casa.

\section{Los espacios privados}

En el caso de los espacios privados, podemos encontrar los hogares de los protagonistas o sus centros de trabajo. Como ya se indicó previamente, el mercado es un espacio público como lugar de intercambio comercial y de tránsito o reunión de diferentes personas. Sin embargo, el local de Alfonso/Pochito específicamente resulta un espacio privado en Sangre inocente, pues en él logran ocultarse y protegerse cuando Calamar y su gente empieza a seguirlos.

Las casas en Sangre inocente son la de Alfonso y la de Michel, el joven que acoge a los fugitivos Cirilo y Pepito. Sus espacios interiores son el comedor y dos cuartos, en ambos casos. El comedor de Alfonso es el lugar donde los personajes escuchan los comunicados y noticias de capturas y enfrentamientos, es donde comentan sobre lo que se vive en Ayacucho, y sobre los abusos y la crítica situación en la que se encuentran los ayacuchanos. Es el espacio íntimo donde Cirilo recuerda el asesinato de sus padres, y donde se sienten refugiados cuando hay apagón o escuchan disparos. Pero es también el lugar desde donde son testigos del allanamiento de una casa cercana y de los gritos de la vecina pidiendo ayuda. El comedor y los cuartos son los espacios que serán violentados por las fuerzas del orden cuando ingresen a capturarlos, y donde verán cómo siembran pruebas para detenerlos. Serán también los espacios donde quedará plasmada la prepotencia y la violencia cuando los jóvenes 
regresen a la casa y encuentren sus cosas destruidas y su dinero robado.

La casa de Michel será, por el contrario, un refugio para los jóvenes que huyen, donde serán acogidos y podrán esconderse al ser perseguidos, o donde se enterarán de los últimos sucesos en la ciudad. Será también en un cuarto de esta casa desde donde verán un camión militar cargado con cuerpos sin vida el día anterior a que encuentren a Alfonso.

En el caso de La última noticia, la casa de Alonso será la principal, aunque existirán algunas escenas en casa de Pedro. La casa de Alonso verá el desarrollo de la pareja de recién casados, ahí comparten sus sueños y temores. También es el espacio donde serán afectados por los apagones, desde donde escucharán las explosiones, donde con los amigos escucharán las noticias de lo sucedido en la ciudad, o donde se hablará de la creciente desconfianza que existe hacia los colegas en los centros de trabajo. Pero será igualmente el lugar donde irrumpirán los senderistas a amenazar a Alonso y su familia, o donde ingresan las fuerzas del orden para capturar a Alonso, mientras su esposa Teresa observa desde la puerta entreabierta el camión militar que se lo lleva.

En esta película, los dos lugares de trabajo son espacios más privados que en la película de Ortega, y se establecen como espacios que representan el desarrollo del conflicto armado. La radio donde trabaja Alonso pasa de ser un espacio musical y de participación a un espacio de creciente tensión - no solo con las fuerzas externas, sino también al interior-, donde es posible denunciar lo que está pasando en la región y dar voz a quienes no la tienen. Se convierte así en centro de disputa de las fuerzas enfrentadas, y termina siendo intervenida por miembros de Sendero y clausurada por las fuerzas del orden.

El colegio será para Pedro el espacio donde se observe el crecimiento de Sendero Luminoso, primero, a través de los indicios de niños que han sido llevados "al monte" para luchar; luego, con la propia desaparición de un joven al que intenta ayudar, con la creciente presencia de pintas y escritos alusivos a la lucha armada, y, finalmente, con la toma del colegio por parte de un grupo de senderistas.

\section{Los espacios de autoridad}

Los espacios de autoridad serán en ambos relatos aquellos controlados por las fuerzas del orden, quienes se han convertido en la autoridad suprema y serán, en los dos casos, lugares de negación y maltrato. Sangre inocente se centra en la casa rosada, espacio de tortura y muerte de varios civiles ayacuchanos, donde Alfonso estará detenido varios días y compartirá el temor y la angustia con otros detenidos en un cuarto hacinado. El patio del local será el lugar de torturas, pero también el de compartir historias con otros detenidos.

La última noticia muestra tres espacios donde se presenta la autoridad: el lugar donde se realiza una conferencia de prensa, la fachada de la comandancia y una celda. La primera da pie 
a un intercambio entre miembros de la prensa y los nuevos encargados militares de la zona, un espacio de posible diálogo que se diluirá rápidamente. La comandancia será el sitio hacia donde vayan los familiares de los detenidos a buscar respuestas, aunque encuentren la negativa y el encubrimiento de las autoridades. La celda es el espacio donde se aísla a Alonso y se le tortura.

\section{Los alrededores}

Los alrededores de la ciudad mostrarán la extensión del terror en Sangre inocente, pues las quebradas y descampados que rodean Ayacucho son los espacios donde los cadáveres son arrojados, los lugares por los que los familiares de Alfonso deambularán buscando su cuerpo, preguntándose por los nombres y el porqué de la gente que encuentran arrojada ahí. También los alrededores será el espacio de huida, la mirada final a la ciudad que dejan, que traerá muerte en la escena final.

En La última noticia, los alrededores serán el espacio donde se muestren con mayor detalle las acciones del conflicto armado, como el ajusticiamiento de un alcalde, la matanza de feligreses, el aniquilamiento de una población o el lugar donde liberan a Alonso luego de hacerle creer que iba a ser ejecutado. Al igual que en Sangre inocente, es también la carretera que los aleja de la ciudad en la que vivían ${ }^{5}$, el espacio de tránsito que los lleva a otro espacio - otro pueblo, otra ciudad-, aunque sin esperanza real.

\section{Discusión}

La ciudad es el espacio donde el conflicto armado se desarrolla en ambas películas, donde se ve reflejado y se establecen las tensiones que llevan a los personajes a sus decisiones finales. El espacio rural, fuera de la ciudad, ahí donde se dio la mayoría de víctimas del CAI, es apenas mostrado o resulta inexistente, lo que otorga mayor importancia a lo ocurrido en las zonas urbanas del conflicto. Como puede esperarse en cualquier producto cultural, se muestran coincidencias en la representación del conflicto armado en estas dos películas, a pesar de tener orígenes diferentes - Lima y Ayacucho-, pero existen diferencias que no se relacionan tanto al origen geográfico, sino que responden a la época en que cada una de ellas fue realizada, a las condiciones en que se hicieron y a la visión de quien ha estado involucrado en el CAI y de quien lo ha vivido desde fuera. Veamos la manera en que esto se ve en cada una de las películas.

El espacio público muestra, en el caso de La última noticia, la manera en que el

5 Aunque visualmente uno puede reconocer más bien la llegada a Lima, antes que la partida de Yurabamba. 
CAI va escalando y cómo lo va transformando. Existe, en este caso, un tránsito desde una situación en que es posible circular por él, sentirse seguro, hasta que se convierte en espacio de peligro. Es a través de la propia transformación de este espacio que se explicitará el cambio de situación y el aumento del conflicto. No es solo a través de lo que ocurre con los personajes que se genera la idea de un conflicto cada vez más crítico, sino que es a través del hecho de sentir el cambio en el espacio donde al inicio del relato la población ejercía su vida comunitaria - ese lugar donde esta vida en común va desapareciendo a medida que avanza la historia- que se genera la sensación de un conflicto que va tomando los espacios de la ciudad. En Sangre inocente, relato más tardío cronológicamente, la ciudad ya inicia de esta manera, como un espacio de vigilancia y peligro. Los personajes circulan por ella, pero saben que no es lugar para estar desprevenidos, es un espacio donde hay que tener cuidado de no ser visto en compañía inadecuada o donde los cadáveres pueden aparecer en cualquier esquina. Lo que ocurre en ese espacio puede afectar de diferente manera a la población - se puede ser testigo o víctima-, de ninguna manera dejará de pasar.

De esta forma, el espacio público es lugar de tensión y peligro, no permite a los pobladores desarrollar su vida normalmente. Las diferentes acciones del relato nos muestran a Alfonso, Cirilo y Pepito atrapados en una balacera, protegiéndose de un coche bomba, encontrando cadáveres cerca de su casa, siendo perseguidos por las fuerzas del orden, teniendo que escabullirse en los mercados, vigilados o perseguidos como sospechosos de terrorismo. Aquellos sitios que deberían ser su ruta para llegar al trabajo o al hogar, para compartir con otros feligreses o tener un momento de descanso parecen desaparecer para esas funciones y son presentados como campos de batalla o donde pueden observarse los resultados de los enfrentamientos. Por su parte, Alonso, Teresa y Pedro dejarán de circular con la alegría que muestran en las primeras escenas, y más adelante deberán huir del enfrentamiento armado el día del desfile, serán capturados por los infantes, deberán retornar presurosos a su casa al escuchar disparos en la calle o mostrarán desconfianza y cautela ante gente que pueda escucharlos. Poco a poco, este espacio se irá desvaneciendo como posibilidad de ser parte de su vida cotidiana. De esta forma, ambas películas representan al espacio público como un lugar donde parte de la vida en comunidad de un pueblo se va diluyendo y se construye como un espacio que es mejor evitar.

Sin embargo, el espacio privado no ofrecerá refugio ante esta situación. Si bien al inicio del relato en ambos filmes las casas son el lugar donde los personajes pueden confiar en los suyos, comentar lo que sucede, hablar de "lo que es mejor no hablar" - en palabras de Pepito-, esconderse o mirar sigilosamente la violencia que ocurre fuera, el desarrollo de las historias hará que estos lugares - al igual que los centros 
de trabajo- dejen de ser refugios, y se conviertan en lugares tan vulnerables como el exterior. En los tiempos violentos del CAI, lo que muestran ambos relatos es que uno ya no puede defenderse o protegerse en el espacio privado. Tanto las fuerzas del orden como Sendero Luminoso invadirán estos espacios, violarán la intimidad y mostrarán la vulnerabilidad de los personajes. Donde antes se vivía la intimidad, donde las paredes marcaban el límite entre el espacio público peligroso y el refugio personal, donde las puertas se cerraban para impedir que penetrara aquello que ocurría fuera, el espacio deja de ofrecerse de esa manera. Las paredes y puertas ya no dan seguridad ni protección, pues las fuerzas del orden irrumpirán y sacarán a quien deseen, o miembros de Sendero Luminoso ingresarán y amenazarán a quienes necesiten, y si se oponen, los eliminarán. Mirar desde dentro lo que sucede en la calle - sea a través de la ventana, como en Sangre inocente, o desde la puerta entreabierta, en $L a$ última noticia - ya no marcará diferencias, pues el peligro se instalará tanto en ese lugar de "afuera" como en el de "adentro".

El tercer espacio de la ciudad que hemos determinado son los espacios de autoridad, y en ambas películas estos serán espacios del terror, el lugar donde la injusticia se da de la manera más cruda por parte de quienes debían proteger a la población. La detención injustificada da paso a la negación de tener bajo custodia a la población civil. Y al tenerlos bajo custodia, los interrogatorios serán motivo para la crueldad y la tortura, que solo finalizarán si es que los miembros de las fuerzas del orden obtienen las respuestas que desean oír, aunque estas sean falsas. Lo que representan estas películas es que la insania del CAI se observa principalmente en los espacios de autoridad -en ambas películas, las acciones de la subversión se muestran brevemente en los espacios públicos-, donde lo que está más ausente es la ley y los derechos que las autoridades deben proteger.

La representación de la ciudad desde el relato costeño y el relato andino muestra sus diferencias en los indicios y detalles que buscan la autenticidad o verosimilitud de los relatos.

La ciudad de La última noticia reafirma constantemente su "andinidad" a partir de los elementos que han generado una imaginería sobre cómo debe verse una ciudad andina. Los encuadres privilegian las paredes descascaradas que muestran la construcción de adobe, los techos de paja, las bases de piedra de las paredes o las puertas con marcos de piedra $^{6}$. Se ubica principalmente en la zona central de la ciudad, en los barrios

6 En una entrevista realizada en septiembre del 2018 al director, este afirmó que le resultó difícil filmar los exteriores porque encontraba a Ayacucho demasiado moderna. 
tradicionales y las paredes de los espacios públicos muestran los signos de la lucha armada, las pintas y lemas en ellas, las banderas comunistas enarboladas que representan la época vivida. Los interiores reflejan la idea de una clase acomodada provinciana - lo que puede ser discutible para el caso de un locutor radial como Alonso- con muebles clásicos pero sólidos, espacios amplios y habitaciones que tienen divisiones muy definidas entre ellas.

Sangre inocente nos refleja una ciudad diferente, una ciudad que al parecer no necesita probar su autenticidad ni verosimilitud. Prefiere las zonas urbanas periféricas de Ayacucho, ahí donde existen casas de adobe, pero rodeadas por casas de ladrillo sin enlucido - producto de la autoconstrucción- o casas con estilo contemporáneo, algunas con puertas de calamina o maderas dispares y otras con estilo urbano moderno. Es, en ese sentido, una ciudad de inicio del nuevo siglo; no hay una preocupación por adecuar su ubicación temporal a los años ochenta porque la película se basa en su propia presencia, en su nombre y locación real. Las pintas senderistas no son comunes en las paredes, aunque la existencia de muertos con carteles se convierte en indicios de lo que sucedió en la época. Los interiores de las casas son austeros, con pocas habitaciones que se dividen por plásticos; cuentan con camastros y andamios por muebles, y afiches en la pared, a diferencia de las camas, aparadores, sillones y cuadros observados en la otra película. Es la representación de una familia de menores recursos, más proclive a la persecución de las fuerzas del orden, con menos recursos para defenderse o salir libres si son atrapados. La excepción es la casa de Michel, personaje que se plantea como miembro de una clase socioeconómica más acomodada, pero cuya vivienda resulta bastante más austera que las casas de un locutor radial o profesor de colegio en la versión limeña.

La construcción de los espacios de autoridad y, en especial, de los lugares de detención, muestran también imaginarios diferentes en los realizadores. $\mathrm{La}$ última noticia parece contener referentes de cinematografías más estadounidenses - amplia celda con un único detenido sentadoy amarradoenelcentro-, mientras Sangre inocente representa hacinamiento, espacios donde las torturas son vistas $-\mathrm{y}$ no sugeridas o en off, como en la película costeña- y las carencias se observan tanto en los muchos prisioneros como en los miembros de las fuerzas del orden, lo que crea un caos en la situación vivida. Estos espacios, aunque restringidos para

7 No puede obviarse que esta película fue realizada en los años finales del CAI, e incluso el material fílmico fue requisado por algún tiempo por las fuerzas del orden. Esta situación hacía más difícil que la producción hiciera pintas subversivas para la película, pues corrían el riesgo de ser acusados de terroristas. 
la gran mayoría de la población, no son ajenos a la configuración de una ciudad que vive el conflicto, pues son parte de la vivencia de los pobladores, que buscan a sus familiares en esos lugares que son parte de su ciudad, aunque no les permitan entrar a ellos.

En La última noticia, la tortura se realiza en la celda del prisionero, espacio dedicado solo a él, mientras que, en Sangre inocente, las torturas se realizan al lado de los demás prisioneros, testigos directos de lo que sucede y de lo que les puede suceder si no colaboran. La individualidad está ausente en lo que hemos llamado espacios de terror en la película de Ortega, pues es la masa de prisioneros quien será violentada y obligada a pasar por un proceso de deshumanización que puede finalizar con su muerte y descarte. En la película de Legaspi el sujeto es individualizado espacialmente, ocupante único de la celda en que es retenido, y donde también es torturado, sin relación con otros posibles detenidos en ese lugar; lo que le pasa lo afecta principalmente a él.

Los alrededores permiten construir un espacio rural en La última noticia, cosa que no ocurre en la película ayacuchana. En esta última, lo urbano y lo rural están entremezclados, son parte de una misma ciudad, donde las afueras no se delimitan específicamente y hay siempre una relación con la ciudad y sus márgenes. Las quebradas y las alturas son parte de una misma ciudad que es delimitada por el terror que se vive en ella. Para La última noticia, fuera de la ciudad está el campo, lo rural, las casas más humildes, que se diferencian de la urbe andina, semicolonial que representa una ciudad Ayacucho sin nombrarla. En esta película, la mayor violencia del CAI - las mutilaciones y las muertes tanto por parte de las fuerzas del orden como de los subersivos- está en esas afueras, y rodea y asfixia a la ciudad.

Hay, entonces, en ambas películas una representación de la ciudad que responde a los directores que la construyen. Hay, en la mirada de Ortega, la posición de quien habla desde su propia ciudad, de quien conoce los espacios y cómo es la vida, el discurrir, las situaciones y los peligros a los que había que enfrentarse. Es una posición casi testimonial, vivencial, que se justifica en sí misma, lo que puede observarse en el texto final, que indica que la historia está basada en cientos de testimonios y en la presentación que Ortega hacía de sí mismo como víctima y prisionero en la casa rosada. La mirada de Legaspi responde a una necesidad de construir el espacio donde no se habita, de hacerlo verosímil para un público que es ajeno a él y que comparte códigos culturales similares. Hay una necesidad de establecer espacios con suficientes referentes de ciudad andina reconocibles en la costa para lograr su verosimilitud.

En todo caso, la construcción que ambas películas hacen de la ciudad coincide en el punto más importante, que es el hecho de que es un espacio que no ofrece garantía alguna, que ya 
no contiene ningún espacio seguro ${ }^{8}$ Lo único que puede salvar a sus protagonistas es el desarraigo, abandonarlo todo a pesar de los deseos de mantenerse en el lugar y de los compañeros que deciden quedarse; un desarraigo que en el caso de Sangre inocente es creciente: sus personajes critican varias veces a quienes abandonan Ayacucho, hasta que ellos no tienen otra opción; mientras, en La última noticia es consecuencia de una amenaza directa por parte de las fuerzas del orden. Ambas películas representan la única alternativa de supervivencia de gente inocente, que debían ocupar otros espacios para continuar su vida. Así, el final también es el mismo en ellas: la visión de los vehículos que llevan a los protagonistas por un camino que los aleja de ese lugar donde ya no les es posible vivir y donde han quedado los cadáveres de sus amigos más cercanos.

Como artefactos culturales que ayudarán en la construcción de la memo-ria cultural, las dos películas ofrecen marcos de referencia a partir de los cuales podremos construir el relato del pasado, configuran un espacio del conflicto que condiciona nuestro entender de los sucesos relatados y de la construcción de memoria. Ambas nos presentan un lugar de peligro, donde la población civil no encuentra refugio ni posibilidades de supervivencia, donde los espacios por los que circulaban tranquilamente o donde podrían refugiarse van desapareciendo gradualmente.

La película de Ortega nos propone un lugar repleto de cadáveres, de muertes diarias, con pobladores urbanos en peligro a pesar de no estar involucrados en lo que sucede ni desear estarlo; un lugar donde el destino está predeterminado, y aun los más inocentes terminan muertos.

En la película de Legaspi, la ciudad es un espacio donde se siente el peligro, aunque sus acciones y consecuencias no se observan abiertamente o con tanta frecuencia, y donde la situación se va volviendo más peligrosa a medida que los personajes se van involucrando más en lo que sucede y toman posiciones firmes sobre ello. Si bien este relato ofrece o escapar o la muerte, también permite que nuevas generaciones - el hijo de Pedrose mantengan firmes en la ciudad.

Ambas versiones quedan como huellas de una futura construcción de la memoria, con matices del nivel de violencia que cada una presenta, pero como representaciones de un espacio andino que cada vez dejaba a sus habitantes menos opciones.

8 Resulta interesante que las dos películas previas de Ortega, con los mismos personajes y lugares, no vislumbren siquiera esta construcción de Ayacucho. Pero ese es material para otro trabajo. 


\section{Referencias}

Ankersmit, F. (1988). Historical representation. History and Theory, 27(3), 205-228. https:// doi.org/10.2307/2504918

Ankersmit, F. (2010). Truth in history and literature. Narrative, 18(1), 29-50. https://doi. org/10.1353/nar.0.0039

Antezana, L., y Cabalin, C. (2018). Memories in conflict in the Chilean public sphere: television fiction and dictatorship. Anàlisi. Quaderns de Comunicació i Cultura, (58), 105-119. doi:https://doi.org/10.5565/rev/analisi.3128

Appadurai, A. (2001). La modernidad desbordada. Dimensiones culturales de la globalización. Buenos Aires: Fondo de Cultura Económica.

Aristóteles. (s. f./trad. 1999). Poética. (V. García Yebra, Ed.) (3. a ed.). Madrid: Gredos.

Barthes, R. (1987). El susurro del lenguaje. Lo verosímil. Barcelona: Paidós.

Bedoya, R. (1995). 100 años de cine en el Perú. Fondo Editorial de la Universidad de Lima.

Bedoya, R. (2009). El cine sonoro en el Perú. Fondo Editorial de la Universidad de Lima.

Benjamin, W. (1929). Una imagen de Proust. Recuperado de http://www.afoiceeomartelo. com.br/posfsa/autores/Benjamin,\%20Walter/Benjamin,\%20Walter\%20-\%20 Una\%20imagen\%20de\%20Proust.PDF

Birulés, F. (1989). Donde no hay narrador, no hay historia. En Historia y narración (pp. 11-22). Barcelona: Paidós Ibérica.

Bustamante, E., y Luna Victoria, J. (2014). El cine regional en el Perú. Contratexto, (22), 189-212.

Bustamante, E., y Luna Victoria, J. (2017). Las miradas múltiples (t. I). Fondo Editorial de la Universidad de Lima.

Cárdenas, C. (2012). ¿Cómo es representado el pasado reciente chileno en dos modos semióticos? Reconstrucción de la memoria en Historia del siglo xx chileno y Los archivos del cardenal. Comunicación: rRvista Internacional de Comunicación Audiovisual, Publicidad y Estudios Culturales, 1(10), 653-665.

Comisión de la Verdad y Reconciliación. (2004). Hatun Willakuy. Versión abreviada del Informe Final de la Comisión de la Verdad y Reconciliación. Lima: Instituto de Democracia y Derechos Humanos de la Pontificia Universidad Católica del Perú.

Comisión de la Verdad y Reconciliación. (s. f). Web oficial. Recuperada de https://www. cverdad.org.pe/

Degregori, C. I. (2011). Qué difícil es ser Dios. Lima: Instituto de Estudios Peruanos.

Edgerton, G. R. (2005). “Where the past comes alive": television, history and popular memory. En J. Wasko (Ed.), A companion to television (pp. 361-377). Nueva Jersey: Blackwell Publishing. 
Erll, A. (2008). Cultural memory studies: an introduction. En A. Erll y A. Nünning (Eds.), Cultural memory studies (pp. 1-15). Berlín: Walter de Gruyter GmbH \& Co.

Erll, A., y Rigney, A. (2010). Introduction: cultural memory and its dynamics. En Mediation, remediation and the dynamics of cultural memory. (pp. 1-11). Berlín: Walter de Gruyter. Recuperado de https://doi.org/10.1515/angl.2010.024

Fairclough, N. (2003). Analyzing discourse. Londres: Routledge.

Foucault, M. (1968). Las palabras y las cosas. Buenos Aires: Siglo XXI.

Ginzburg, C. (2013). Mitos, emblemas e indicios. Morfología e historia. Barcelona: Gedisa.

Gledhill, C. (2003). Genre and gender: the case of soap opera. En S. Hall (Ed.), Representation (pp. 337-384). Londres: The Open University.

Halbwachs, M. (1995). Memoria colectiva y memoria histórica. Revista Española De Investigaciones Sociológicas, 69(95), 209-219. https://doi.org/10.2307/40183784

Hall, S. (2003). The work of representation. En S. Hall (Ed.), Representation (pp. 1-74). The Open University.

Heyne, E. (1987). Towards a theory of literary nonfiction. Modern Fiction Studies, 33(3), 479-490.

Hoskins, A. (2001). New memory: mediating history. Historical Journal of Film, Radio and Television,21(4),333-346. Recuperadodehttps://doi.org/10.1080/01439680120075473

Jelin, E. (2001). ¿De qué hablamos cuando hablamos de memorias? En E. Jelin, Los trabajos de la memoria (pp. 17-38). Recuperado de http://www.centroprodh.org. mx/impunidadayeryhoy/DiplomadoJT2015/Mod2/Los\%20trabajos\%20de\%20 la\%20memoria\%20Elizabeth\%20Jelin.pdf

Jelin, E. (2002). Historia y memoria social. En E. Jelin, Los trabajos de la memoria (pp. 63-78). Recuperado de http://www.centroprodh.org.mx/ impunidadayeryhoy/DiplomadoJT2015/Mod2/Los\%20trabajos\%20de\%20 la\%20memoria\%20Elizabeth\%20Jelin.pdf

Jodelet, D. (2008). El movimiento de retorno al sujeto y el enfoque de las representaciones sociales. Connexion, 3(5), 25-46.

Klinkenberg, J.-M. (2006). Manual de semiótica general. Fundación Universidad de Bogotá Jorge Tadeo Lozano.

Marcel, J. C., y Mucchielli, L. (2008). Maurice Halbwachs's mémoire collective. En A. Erll y A. Nünning (Eds.), Cultural memory studies (pp. 141-149). Berlin: Walter de Gruyter GmbH \& Co.

Marin, L. (2001). On representation. Stanford: Stanford University Press.

Moscovici, S. (1979). El psicoanálisis, su imagen y su público. Buenos Aires: Editorial Huemul. Recuperado de https://taniars.files.wordpress.com/2008/02/moscoviciel-psicoanalisis-su-imagen-y-su-publico.pdf 
Moscovici, S. (1988). Notes toward a description of social representation. European Journal of Social Psychology, (18), 211-250.

Neiger, M., Meyers, O., y Zandberg, E. (Eds.). (2011). On media memory. Collective memory in a new media age. Londres: Palgrave Macmillan.

Nora, P. (2008). Les lieux de mémorie. Montevideo: Trilce.

Olick, J. (2008). From collective memory to the sociology of mnemonic practices and products. En A. Erll y A. Nünning (Eds.), Cultural memory studies (pp. 151-162). Berlin: Walter de Gruyter.

Potter, J. (1998). La representación de la realidad. Discurso, retórica y construcción social. Barcelona: Paidós Ibérica.

Rezende, L. A. (2013). Microfísica do documentário. Río de Janeiro: Beco do Azogue.

Rodríguez, T. (2002). Representar para actuar. Representar para pensar. Breves notas metodológicas. En C. Del Palacio Montiel (Ed.), Cultura, comunicación y política (pp. 25-40). Universidad de Guadalajara.

Rose, G. (2002). Visual methodologies. Wiltshire: Sage.

Rosenstone, R. A. (1995). Visions of the past: the challenge of film to our idea of history. Cambridge, Estados Unidos: Harvard University Press.

Sturken, M. (1997a). Reenactment, fantasy, and the paranoia of history: Oliver Stone's docudramas. History and Theory, 36(4), 64-79.

Sturken, M. (1997b). Tangled memories: The Vietnam War, the AIDS epidemic, and the politics of remembering. University of California Press.

Sturken, M. (2007). Tourists of history. Memory, kitsch, and consumerism from Oklahoma City to Ground Zero. Duke University Press.

Tomashevski, B. (1978). Temática. En Teoría de la literatura de los formalistas rusos (pp. 199-231). México: Siglo XXI.

Weingarten, M. (2006). The gang that wouldn't write straight: Wolfe, Thompson, Didion, Capote, and the new journalism revolution. Nueva York: Three Rivers Press.

White, H. (2003). El texto histórico como artefacto literario. Barcelona: Paidós.

Zecchetto, V. (2002). La danza de los signos. Quito: Abya Yala. 